\title{
Treatment of asthma: From the child to the adult
}

\begin{abstract}
A sthma is one of the most common respiratory ailments in industrialized countries and still results in unacceptable morbiclity and mortality rates. Our understanding of the mechanisms of development of asthma has increased significantly in the past few years and, as a result, its management has changed progressively. Many consensus statements providing treatment guidelines have been published for both adult and childhood asthma. Usually, the pediatric and adult aspects of asthma management have been considered separately. However, we now realize that the physiopathology of asthma is quite similar in children and arfults and that the approach to treatment should be based on similar grounds, with an emphasis on environmental control and early treatment of airway inflammation.

At a symposium in Montreal, Quebec on December 4, 1993, representatives of the pediatric and adult milieux gathered under the auspices of the Quebec Thoracic Society, the Quebec Asthma Education Network and the University of Montreal Continuing Medical Education Bureau to discuss a longitudinal approach to asthma treatment in adults and children. Reporting from this last symposiun and taking into account recently published studies, the contributors to this supplement review many critical issues in asthma treatment and try to answer such questions as: Do asthmatic children become asthmatic adults and, if so, can we prevent this? Is the suggested role of inhaled corticosteroids as first-line drugs in asthma justified? Can corticosteroids lead to asthmat remission in children or adults? Is there still a place for nonsteroidal bronchial anti-inflammatory agents or theophylline? Is regular use of beta2-agonists really detrimental? How should we use long-acting betaz-agonists"? Should we provide asthma education and action plans to all asthmatic patients and, if so, how and when? Should patients measure their peak expiratory flow rates regularly? What will be the main developments in asthma treatment over the next few years? Is it possible to see any cure coming for asthma? What is the 'Quebec Asthmil Education Network'?

The contributors to this supplement do not want to duplicate established asthma treatment guidelines, but wish to provide further discussion around the controversies in current asthma treatment. We hope that it will prove useful to those who have to make day-to-day therapeutic decisions in children or iddults presenting with asthma, and be a source of stimulation to those searching for new approaches and treatments aimed at reducing the still excessive morbidity associated with this disease.

We wish to thank those pharmaceutical companies who generously supported the symposium, and Astra and Glaxo for the sponsorship of this proceedings.
\end{abstract}

Louis-Philippe Boulet MD

Centre de Pneumologie de l'Hòpital Laval

Sainte-Foy, Québec
Robert Thivierge MD

Hôpital Sainte-Justine

Montréal, Québec 


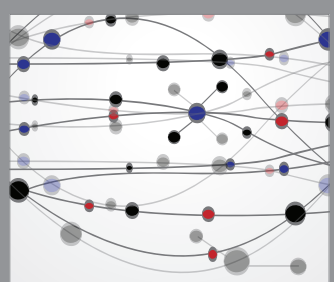

The Scientific World Journal
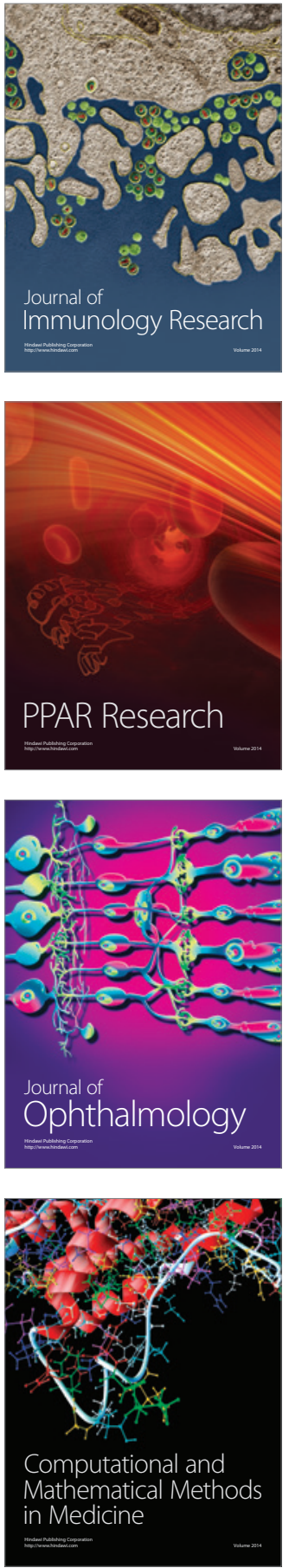

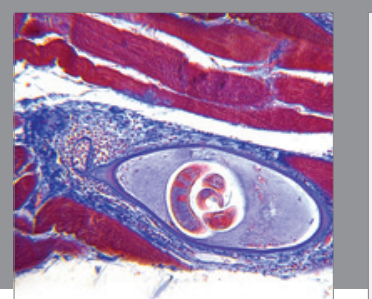

Gastroenterology Research and Practice

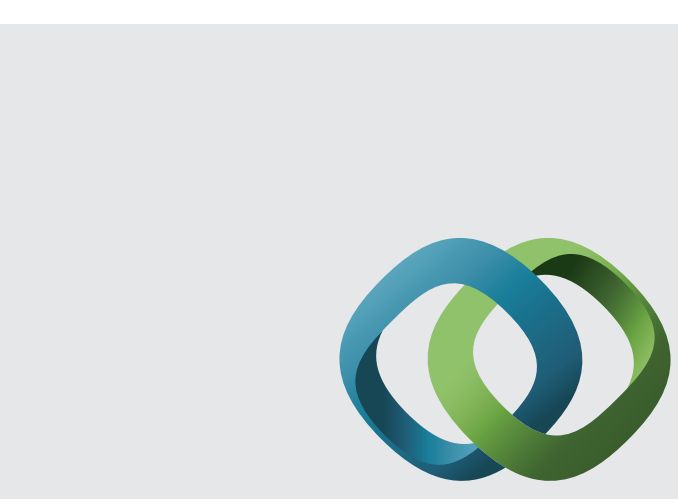

\section{Hindawi}

Submit your manuscripts at

http://www.hindawi.com
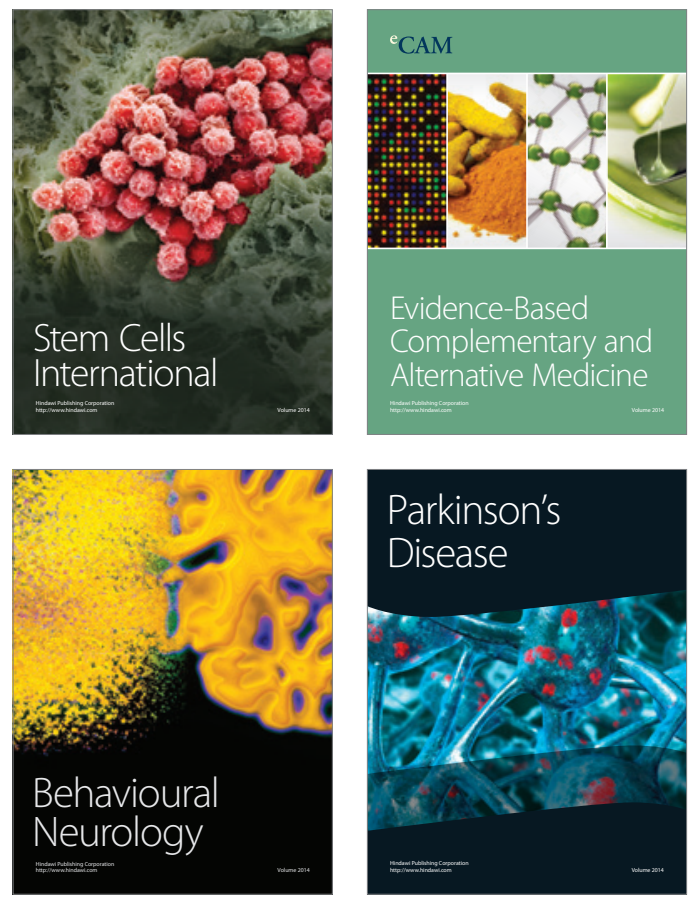
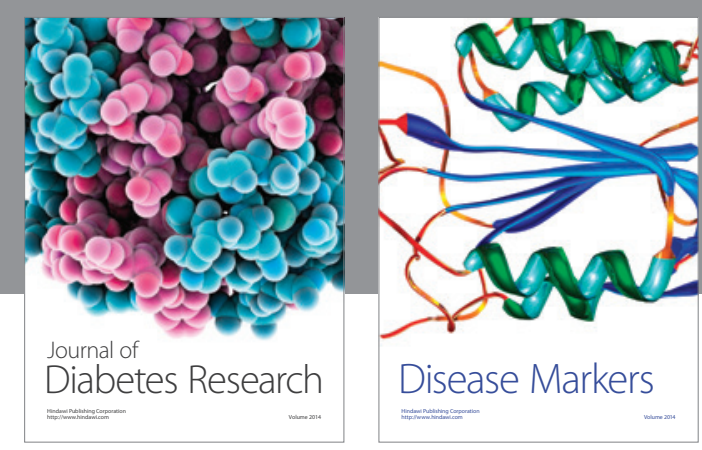

Disease Markers
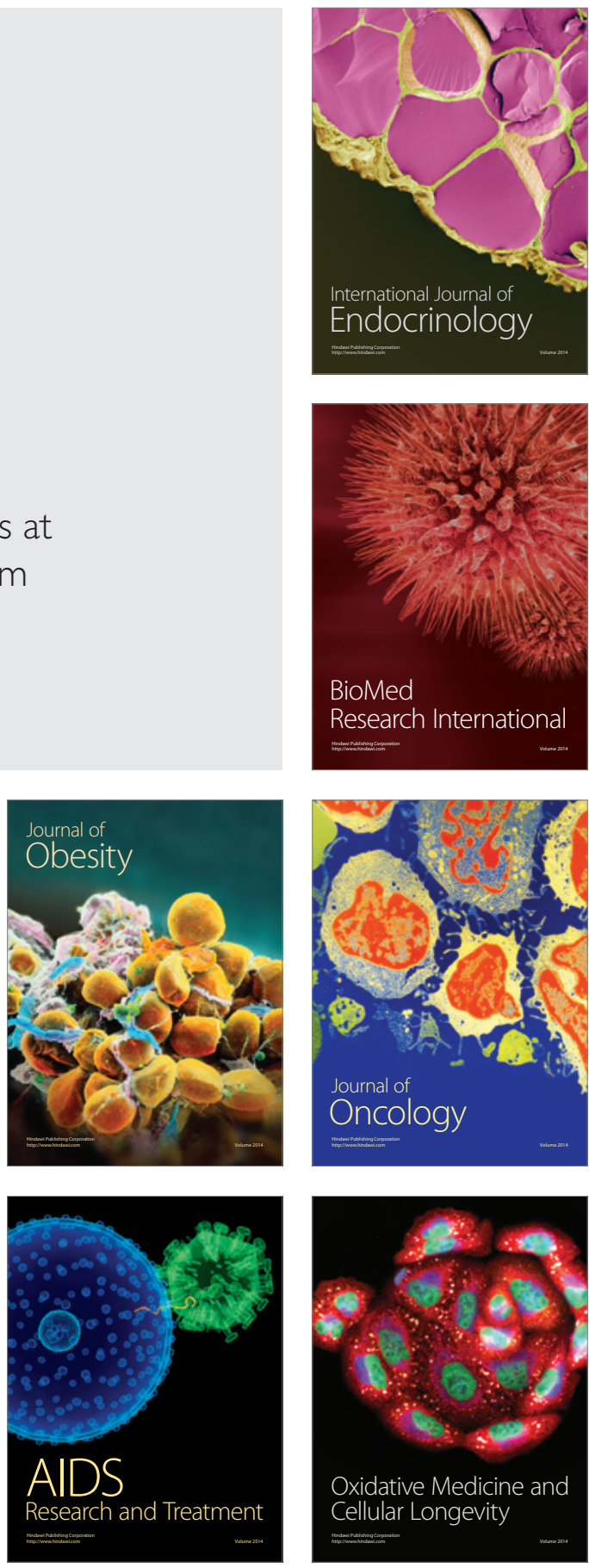